\title{
Cartografías socio-estatales y subjetividades. Un recorrido sobre programas sociales en la contemporaneidad
}

\section{María Pía Castro Ruiz ${ }^{1}$ \\ Universidad Nacional de San Luis}

\section{Reseña del libro}

Becher, Y. (2017). Cartografías socio-estatales y subjetividades. Un recorrido sobre programas sociales en la contemporaneidad. Buenos Aires: compaginado desde TeseoPress. ISBN: 978-987-42-5091-9, pp.: 210.

Material original autorizado para su primera publicación en el Journal de Ciencias Sociales, Revista Académica de la Facultad de Ciencias Sociales de la Universidad de Palermo.

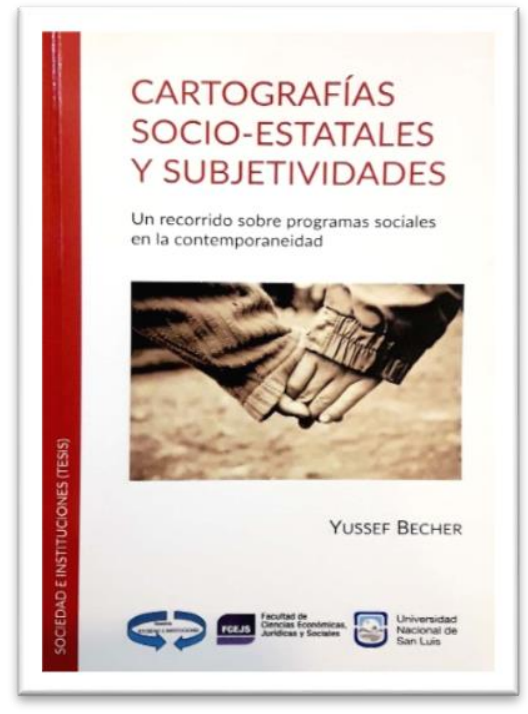

Resumen: Cartografías socio-estatales y subjetividades es el resultado de una investigación para la culminación de la Carrera de Posgrado Maestría en Sociedad e Instituciones de la Universidad Nacional de San Luis. El libro emprende un análisis respecto a las concepciones de sujeto en tres programas sociales argentinos implementados de 2003 a 2014: Plan Jefas y Jefes de Hogar Desocupados (PJJHD), Asignación Universal por Hijo para Protección Social (AUH) y Programa de Respaldo a Estudiantes Argentinos (PROGRESAR). Desde la aplicación del PJJHD en 2003, pasando por la AUH en 2009 hasta llegar al PROGRESAR en 2014, se visualiza un progreso en distintos aspectos asociados al ejercicio de derechos sociales.

\footnotetext{
1 Lic. Ciencia Política (UNRC). Maestranda de la Carrera de Posgrado Maestría en Sociedad e Instituciones, FCEJS- UNSL. Profesora Auxiliar de los espacios curriculares: Sociología de la Educación/ Formación Ética y Ciudadana II. Profesorado de Educación Primaria IFDCVM. Profesora Auxiliar de los espacios curriculares de Historia Económica Argentina (CPN y Licenciatura en Administración) e Historia Social y Económica Argentina (Licenciatura en Trabajo Social) FCEJS- UNSL. Correo electrónico: mapiacastro@hotmail.com
} 
El libro se encuentra dividido en dos grandes partes. En la primera, encontramos aspectos metodológicos que guiaron la investigación, así como también un recorrido histórico sobre las diferentes concepciones de sujeto en los programas sociales. En la segunda, Becher se aboca a justificar su elección respecto de las tres intervenciones objeto de estudio, resaltando el contexto socio-político en el que son implementadas. Finalmente, analiza la concepción de sujeto prevaleciente en los programas sociales: PJJHD, AUH y PROGRESAR.

En el primer capítulo el autor explicita aspectos metodológicos vinculados al problema de investigación, remitiendo al vacío teórico en relación al análisis del sujeto de los programas sociales. Esta situación de vacancia, lo orienta a "construir un marco de referencia para posteriores desarrollos, que pueden incluir una reformulación de los que presenta este estudio mediante otras indagaciones teóricas" (p. 32).

El capítulo dos emprende un recorrido teórico respecto de tres concepciones del sujeto de los programas sociales: beneficiario, usuario-receptor y destinatario; cada una de las cuales guarda una vinculación particular con el contexto histórico en el cual fue utilizada.

En el apartado tres, Becher profundiza el análisis de la concepción de beneficiario de los programas sociales, criterio que prevaleció durante el auge de las políticas neoliberales. Los años 90 se caracterizaron por la aplicación de políticas focalizadas, con escasos recursos y que concebían al sujeto como un mero "beneficiario", objeto de la asistencia estatal a partir de una especie de dádiva traducida en una escueta suma de dinero.

El capítulo cuatro se centra en el análisis de la concepción del sujeto como usuarioreceptor; conceptualización que se halla ligada a la aplicación de Programas de Transferencia Condicionada de Ingresos (PTCls). En el marco de estos programas, "el sujeto recibe una transferencia a cambio del cumplimiento de condicionalidades que lo convierten en usuario de servicios públicos tales como educación primaria, salud, capacitación laboral, etc." (p. 61).

La primera parte del libro culmina con el capítulo cinco en el que se analiza la concepción del sujeto como destinatario. Esta consideración implica el reconocimiento del sujeto como titular de derechos con la potestad de demandarle al Estado determinadas acciones y prestaciones. Esta concepción se encuentra ligada al enfoque basado en derechos, el cual "considera al derecho internacional sobre los derechos humanos como un marco conceptual (...) capaz de orientar el proceso de formulación, implementación y evaluación de políticas en el ámbito del desarrollo" (citando a Abramovich, 2006, p.35).

La segunda parte del libro inicia con el capítulo seis en el que se plantea a los programas sociales como parte de un proceso político más amplio vinculado a la planificación de políticas públicas. Así, los programas sociales son concebidos como la acción concreta 
del actor (Estado) frente al diagnóstico y detección de una situación problemática que reclama atención y solución. El apartado culmina con una fundamentación de la selección de los tres programas sociales objeto de abordaje: PJJHD, AUH y PROGRESAR. Entre aquellos argumentos se señala el contexto histórico particular en el que esas intervenciones fueron implementadas y la masividad que alcanzaron.

En el capítulo siete, a partir del análisis de los decretos regulatorios de los tres programas, el autor genera cuatro categorías teóricas: beneficiario, usuario-receptor, destinatario e inclusión-derechos, alrededor de las cuales responde a la pregunta: ¿Cómo conciben al sujeto el Plan Jefes y Jefas de Hogar Desocupados, la Asignación Universal por Hijo para Protección Social y el Programa de Respaldo a Estudiantes Argentinos? A partir del proceso de indagación teórica se advierte que ninguna de las tres intervenciones abraza una concepción determinada, sino que los documentos oficiales contienen elementos pertenecientes a diferentes maneras de concebir al sujeto de los programas sociales.

En el caso del PJJHD se observa una preeminencia de aspectos vinculados a la categoría beneficiario. Esto último se debe a que este plan no preveía una mayor extensión como así tampoco la posibilidad de universalizar la medida. Además, ponía el acento en la condición de desempleo para acceder a la prestación. Otra de las dificultades que presentó el PJJHD fue la excesiva documentación que exigía para la inscripción, lo cual generó que muchas personas de sectores vulnerables quedaran excluidas. Este plan nace a partir de un Decreto de Necesidad y Urgencia (DNU) del Poder Ejecutivo en el año 2002. Las sucesivas modificaciones al programa también fueron realizadas a partir de decretos. En este sentido, no se evidenció un avance para que, a partir del adecuado tratamiento parlamentario, el Plan se convirtiera en ley.

La AUH ha significado una reorientación en la definición de políticas sociales. A diferencia del PJJHD, la Asignación parte de reconocer a la pobreza como un fenómeno estructural y multidimensional. Un avance importante es la universalización que logra de las asignaciones familiares, las cuales, antes de su implementación, solo constituían un derecho para los trabajadores que se desempeñan en el mercado formal de trabajo. Así, se concibe la estrategia de intervención no como un programa, sino como una extensión del sistema de asignaciones familiares al que ya tenían acceso otros sectores de la sociedad. En lo referente a la progresividad, en el año 2015, la entonces presidenta Cristina Fernández envió un proyecto de ley al Congreso con el objetivo de que la AUH sea actualizada con el mismo cálculo con el que se actualizan los haberes jubilatorios. Tras la aprobación del proyecto, el monto aumenta dos veces al año, en los meses de marzo y septiembre.

Algo que se observa en este programa es una fuerte presencia del cumplimiento de las condicionalidades. En efecto, si esas exigencias no se cumplen y registran en tiempo y 
forma, se procede a la suspensión de la transferencia económica. Este predominio de las condicionalidades lleva a considerar que la concepción de sujeto que prevalece es la de usuario-receptor, consideración que, como hemos mencionado, se reitera en todos los PTCls.

En lo atinente a su aspecto formal, la AUH también se encuentra regulada por un DNU del año 2009. Más allá de ello, tanto la Asignación como el PROGRESAR han avanzado en cuanto al debate al interior del Congreso para convertirse en leyes, evitando, de este modo, estar sujetos a los avatares del decisionismo político.

Por último, el autor afirma que el PROGRESAR es el programa social que más se acerca a la concepción de sujeto como destinatario. Si bien contiene exclusiones y penalidades, son bastas las menciones que permiten afirmar que el documento que lo regula contiene medidas vinculadas a la evaluación y monitoreo, a una correcta institucionalidad social y a una tendencia a la progresividad. EI PROGRESAR mejoró muchos aspectos a un año de su implementación: una reducción considerable de la presentación de constancias de cumplimiento, la elevación de un tope del salario a tres para considerar al joven, la posibilidad de incorporación de nuevos destinatarios y el incremento del monto de la transferencia de ingresos.

Desde la aplicación del PJJHD en 2003, pasando por la AUH en 2009 hasta llegar al PROGRESAR en 2014, se visualiza un progreso en distintos aspectos asociados al ejercicio de derechos sociales. Para poder comprender este avance se debe considerar el contexto socio-político en el que las políticas fueron aplicadas. Con la asunción de Néstor Kirchner en 2003 se produce un proceso de modificación de la matriz estatal. En el marco de ese viraje ideológico los derechos humanos adquieren un rol protagónico en la agenda pública. Este protagonismo de los derechos humanos favoreció la tematización del enfoque de derechos en los procesos de planificación de políticas sociales. Si bien lo anterior no nos habilita a afirmar que los tres programas abordados hayan sido definidos en base a los estándares en derechos humanos sostenidos por aquel enfoque, sí nos permite advertir que se trata de medidas tendientes a lograr una mayor inclusión ligada al ejercicio de derechos. Esta nueva perspectiva en el diseño de programas sociales es, indudablemente, el camino correcto para avanzar en la construcción del sujeto como destinatario.

Becher concluye recomendado la incorporación de tres enfoques en la elaboración de programas sociales: el enfoque de género, el generacional y el territorial. Aquellas perspectivas, junto a los estándares del enfoque basado en derechos, constituyen decisiones políticas fundamentales si lo que se pretende es avanzar en la consideración de un sujeto empoderado como verdadero destinatario de la intervención estatal. 